\title{
Taxon-specific differences in photoacclimation to fluctuating irradiance in an Antarctic diatom and a green flagellate
}

\author{
M. A. van Leeuwe ${ }^{1, *}$, B. van Sikkelerus ${ }^{1}$, W. W. C. Gieskes ${ }^{1}$, J. Stefels ${ }^{1,2}$ \\ ${ }^{1}$ Department of Marine Biology, University of Groningen, PO Box 14, 9750 AA Haren, The Netherlands \\ ${ }^{2}$ Present address: Laboratory for Plant Physiology, University of Groningen, PO Box 14, 9750 AA Haren, The Netherlands
}

\begin{abstract}
Photoacclimation towards rapid changes in irradiance was studied in 2 Antarctic microalgae, the diatom Chaetoceros brevis (Bacillariophyceae) and the flagellate Pyramimonas sp. (Prasinophyceae). Both species were subjected to 3 different light regimes. Two regimes of vertical mixing (1:1 $\mathrm{h}$ and 3:3 h high light:low light) were superimposed on a diurnal light cycle mimicking the solar sine. For both species, maximum growth was recorded at the fastest rates of light fluctuation $(1: 1 \mathrm{~h})$. The light regimes had a minor effect on growth rates of the flagellate but growth in the diatom was reduced significantly at moderate rates of mixing $(3: 3 \mathrm{~h})$. While xanthophyll cycling was active in both species, fluorescence analysis with a dual-modulated fluorometer showed that down-regulation of photosynthetic efficiency was more pronounced in Pyramimonas sp. (ca. $50 \%$ ) than in C. brevis (ca. 30\%). The ratio of photoprotectors to chlorophyll a was not significantly affected by the light regime, neither in the flagellate nor in the diatom. In the flagellate, state transition offered an additional means of energy dissipation during the periods of high irradiance. The diatom apparently acclimated to the average light intensity received and not to the maximum irradiance. It can be reasoned that this strategy led to photodamage during the $3: 3 \mathrm{~h}$ cycling. It is argued that enhanced maintenance costs associated with necessary repair processes can explain the reduced growth rate that was observed. The ecological consequences for large bloom-forming diatom species are briefly discussed.
\end{abstract}

KEY WORDS: Photoacclimation · Fluorescence · Xanthophyll pigments · Fluctuating light • Absorption · Chaetoceros brevis · Pyramimonas sp.

\section{INTRODUCTION}

Light is an important factor controlling phytoplankton growth in the marine environment. Adaptation of microalgae to fixed light regimes has received considerable attention and has provided detailed knowledge on the structure and functioning of their photosynthetic apparatus (e.g. Falkowski 1980, Falkowski \& LaRoche 1991). Photoacclimation of phytoplankton to variable light conditions, as generally experienced by phytoplankton in the natural environment, is less well described (e.g. Marra 1978, Gallegos et al. 1983, Ibelings et al. 1994). Wind mixing and surface waves induce turbulence in the upper water column, by which micro-algal cells are transported through the euphotic zone at various scales of length and time. Within hours, cells may experience light intensities from inhibiting, at the surface, to near limiting, deeper in the water column (Harding et al. 1987). The response of cells towards ambient light conditions involves optimization of their photosystems in such a way that energy generation and utilization are in balance (Henley \& Ramus 1989), (Kana et al. 1997). At high light intensities, more energy will be generated than can be used, which results in photodamage. The response to prevent this not only includes a reduction 
in size of the photosynthetic apparatus, but also the synthesis of photoprotecting pigments and associated changes in membrane structure. Under low light conditions on the other hand, cells need to expand their light-harvesting complexes. Such responses involve time scales of hours to days (Marra 1980). The process of photoacclimation to a dynamic climate runs on much shorter time scales, i.e. minutes to hours (e.g. Post et al. 1984, Cullen \& Lewis 1988). In this case, photoacclimation does not depend so much on the synthesis of structural components, but rather requires flexibility of the photosystems and is primarily aimed at preventing photoinhibition during exposure to higher irradiance levels. Several non-photochemical quenching processes that are involved in the regulation of energy distribution in the short-term have been described (see Horton et al. 1996, Muller et al. 2001 for review). Energy-dependent quenching ( $\mathrm{qE}$ ) and state-transition quenching (qT) are processes that operate on time scales in the order of minutes to hours. Energydependent quenching is $\mathrm{pH}$-dependent and activates conversion of the pigments of the xanthophyll cycles (diatoxanthin, diadinoxanthin, violaxanthin, antheraxanthin and zeaxanthin) (Demmig-Adams et al. 1996). The importance of the qT component is species dependent. Moreover, the efficiency of energy dissipation based on state transitions is still a topic of debate. (Saito et al. 1983, Allen 1995). The importance of the 3-dimensional structure of the thylakoid membrane has also increasingly been receiving more attention (e.g. Gilmore 1997).

Various algal groups possess different types of photosystems, with varying pigment composition and associated differences in the architecture of the membrane structure (Richardson et al. 1983). The nature of these photosystems may affect the flexibility of the membranes and thus, the capacity of photoacclimation. In view of the ecological significance of rapid fluctuations in light, the question arises as to whether species that carry different photosystems are equally capable of photoacclimation. This question is especially relevant in vast areas of the Southern Ocean, where frequently occurring storms induce severe mixing of the water column (Mitchell \& Brody 1991). Here, the various habitats, which can be defined according to light climate, are characterized by a typical algal distribution. Whereas small flagellates dominate areas with a dynamic light regime, diatoms appear to be the bloomforming species under stable light conditions in frontal zones and at the marginal ice zone (Cailliau et al. 1996). Both algal groups have distinctly different pigment signatures and so may display different means of photoacclimation. Diatoms appear tolerant to high levels of irradiance (e.g. Richardson et al. 1983); however, contradictory insights remain on their susceptibility to variable light conditions (Hegseth 1989, Ibelings et al. 1994, Flameling 1998). Very little is known about the sensitivity of non-diatom species to photoinhibition (e.g. Kroon 1994, Flameling \& Kromkamp 1995).

To obtain greater insight into factors controlling the Antarctic ecosystem, a study was carried out on photoacclimation towards rapid changes in light intensity by 2 typical Antarctic phytoplankton species, namely the diatom Chaetoceros brevis and the flagellate Pyramimonas sp. We show that, despite apparent photoacclimation, the diatom experiences growth reduction at moderate rates of light fluctuations. For our purposes, photosynthetic efficiency was studied by means of fluorescence analyses. The light-harvesting capacity was determined by analyses of the pigment composition and recording of in vivo absorption spectra.

\section{MATERIALS AND METHODS}

Culture conditions. Experiments were carried out with 2 common Antarctic microalgae: Chaetoceros brevis (Bacillariophyceae) (CCMP 163) and Pyramimonas sp. (Prasinophyceae; isolated from the Weddell Scotia Confluence, RUG collection, Buma et al. 1991). Before starting the experiments, the cultures were preconditioned for several generations to the experimental conditions. Cultures were grown in $1 \mathrm{l}$ Erlenmeyer flasks on $\mathrm{F} / 10$ medium $\left(140 \mu \mathrm{M} \mathrm{NO}{ }_{3}, 7.5 \mu \mathrm{MPO}_{4}\right.$; based on Admiraal \& Werner 1983) at $4^{\circ} \mathrm{C}$ and kept in suspension by daily shaking. Three different light regimes were enforced by means of a Venetian Blind system that was mounted between the cultures and the light source (Philips MHN-TD). The system consisted of horizontal slats, of which the position could be altered by a step motor. Two independent units were used to enforce variable light conditions; the diurnal intensity of solar irradiance was simulated by a sinusoidal light course (referred to as the 'sinusoidal' light regime; see Fig. 1). Vertical mixing was simulated by 2 different oscillations $11: 1 \mathrm{~h}$ and $3: 3 \mathrm{~h}$ of high vs. low light; referred to as the ' $1: 1 \mathrm{~h}$ ' and the ' $3: 3 \mathrm{~h}$ ' light regimes) that were superimposed on the solar pattern (see Fig. 1). The time scales that were chosen relate to near-surface windmixing associated with Langmuir circulation (Denman \& Gargett 1983). The Venetian blinds used to enforce vertical mixing were equipped with neutral density filters transmitting $30 \%$ irradiance. The maximum intensity of irradiance $\left(400 \mu \mathrm{mol}\right.$ photons $\left.\mathrm{m}^{-2} \mathrm{~s}^{-1}\right)$ was chosen as the average ambient irradiance level at 5 to $15 \mathrm{~m}$ (based on an attenuation coefficient of $0.06 \mathrm{~m}^{-1}$; see van Oijen et al. 2003) and was similar for all conditions. The total photon flux density (PFD) received by the algae over the full light period was similar for the $3: 3 \mathrm{~h}$ and $1: 1 \mathrm{~h}$ light regimes, and measured $70 \%$ of the 
PFD under 'non-mixing' conditions. We chose to maintain maximum intensities during midday at a similar level, in order to be able to interpret the data in terms of potential effects of photoinhibition. The light inside the flasks was measured with a spherical sensor (Biosperical Instruments QSL-100).

Photosynthetic parameters. Growth rates: Cell numbers were determined by inverted microscopy after fixation with Lugol's solution. Growth rates were calculated following the formula:

$$
\mu=1 / t\left[\ln \left(N_{t} / N_{0}\right)\right]
$$

where $\mu\left(\mathrm{d}^{-1}\right)$ is the growth rate, $t$ is the period of time after the start $t=0$ of the experiment and $N$ is the number of cells. Cell volume was determined with a Coulter counter.

Fluorescence measurements: Chlorophyll a fluorescence was measured with a dual-modulated fluorometer (Photosystem Instruments) (Trtílek et al. 1997). Minimal $\left(F_{0}\right)$ and maximum fluorescence $\left(F_{\mathrm{m}}\right)$ were recorded after dark adaptation $\left(5 \mathrm{~min}\right.$ at $4^{\circ} \mathrm{C}$, sufficient to attain stabilization of the fluorescence signal for all light regimes). The maximum quantum yield of photosynthesis $\left(\Phi_{\mathrm{m}}\right.$ referred to as photosynthetic efficiency) was calculated as $\left(F_{\mathrm{m}}-F_{0}\right) / F_{\mathrm{m}}$ (Krause \& Weis 1991).

Absorption spectra: In vivo light absorption spectra (400-700 nm) were recorded using a Varian-Cary integrating sphere. Data were corrected for scattering by subtracting a baseline value as measured at $725 \mathrm{~nm}$. Baseline correction was applied against the background of filtered seawater medium. The total spectral irradiance absorbed per cellular carbon $\left(A Q_{\mathrm{ph}}, \mathrm{mmol}\right.$ photons mol $\mathrm{C}^{-1} \mathrm{~s}^{-1}$ ) was calculated as:

$$
A Q_{\mathrm{ph}}=\int_{400}^{700} a_{\mathrm{c}}(\lambda) \times Q(\lambda) \delta(\lambda)
$$

where $a_{\mathrm{C}}(\lambda)$ is the wavelength-specific absorption $\left(\mathrm{m}^{2}\right.$ mol $\left.\mathrm{C}^{-1}\right), Q(\lambda)$ is spectral irradiance (mmol photons $\mathrm{m}^{-2}$ $\mathrm{s}^{-1}$ ) and $\delta(\lambda)$ is the wavelength interval of the spectral band $(2 \mathrm{~nm})$. The spectrally averaged chl a-specific absorption cross-section $\left(\bar{a}_{\mathrm{ph}}, \mathrm{m}^{2} \mathrm{mg}^{-1} \mathrm{chl} a_{\text {; }}\right.$ in which $a_{\text {chl }}(\lambda)$ is expressed in $\mathrm{m}^{2} \mathrm{mg}^{-1} \mathrm{chl}$ a) was calculated as:

$$
\bar{a}_{\mathrm{ph}}=\frac{\int_{400}^{700} a_{\mathrm{chl}}(\lambda) \times Q(\lambda) \delta(\lambda)}{\int_{400}^{700} Q(\lambda) \delta(\lambda)}
$$

The quantum efficiency of growth $\left(\Phi_{\mu}\right)$ could then be calculated according to Falkowski et al. (1985):

$$
\Phi_{\mu}=(\mu \times \mathrm{POC} \times F) /\left(\bar{a}_{\mathrm{ph}} \times \mathrm{chl} \times I_{0}\right)
$$

where $\Phi_{\mu}$ is the efficiency of conversion of quanta into carbon ( $\mu \mathrm{mol} \mathrm{C}$ mol quanta $\left.{ }^{-1}\right), \mu$ is the specific growth rate $\left(\mathrm{d}^{-1}\right)$, POC is the cellular carbon content $\left(\mathrm{pg} \mathrm{cell}{ }^{-1}\right)$, $\bar{a}_{\text {ph }}$ is the spectrally averaged, chl a-specific absorption cross-section $\left(\mathrm{m}^{2} \mathrm{mg}^{-1} \mathrm{chl}\right.$ a), chl is the cellular chl a content (pg cell ${ }^{-1}$ ) and $I_{0}$ is the incident irradiance (mol quanta $\mathrm{m}^{-2} \mathrm{~s}^{-1}$ ). $F$ is a constant used to convert units from pg $\mathrm{C}$ to $\mu \mathrm{mol} \mathrm{C}$ and from $\mu \mathrm{mol}$ quanta $\mathrm{m}^{-2} \mathrm{~s}^{-1}$ to mol quanta $\mathrm{m}^{-2} \mathrm{~d}^{-1}$ (i.e. $16 \mathrm{~h}$ daylight).

Chemical analysis. POC and PON: Particulate carbon $(P O C)$ and nitrogen $(P O N)$ were analyzed on a CHNS elemental analyzer type EA 1110 (Interscience) after gentle filtration $(<15 \mathrm{kPa})$ of small aliquots over pre-combusted GF/F Whatman filters.

Pigments: Samples were filtered gently $(<15 \mathrm{kPa})$ over GF/F Whatman filters and subsequently flashfrozen in liquid nitrogen. Samples were freeze-dried to increase extraction efficiency and to retard possible deleterious enzyme activities. After freeze-drying, pigments were extracted in $90 \%$ acetone and analyzed by high-performance liquid chromatography on a Waters system equipped with a photodiode array, according to (Kraay et al. 1992). A Waters DeltaPak reversed-phase column (C18, fully end-capped) was used. The sample was injected via a cooled autosampler $\left(6^{\circ} \mathrm{C}\right)$ between 2 plugs of water. Pigment standards were obtained from Sigma.

Intracellular dissolvable carbohydrates: Cells were collected on pre-combusted GF/F Whatman filters under low vacuum $(<15 \mathrm{kPa})$. The filters were treated for $1 \mathrm{~h}$ with hot water $\left(80^{\circ} \mathrm{C}\right)$ to extract total waterextractable carbohydrates. Carbohydrates were determined as glucose equivalents by the phenol-sulphuric acid method using glucose as a standard (Liu et al. 1973). Samples were only collected from cells cultured under the 3:3 $\mathrm{h}$ and 1:1 h light regimes.

Sampling strategy and statistical analyses. Experiments were performed in triplicate, albeit not sampled at all time intervals (see Figs. 1 to 3). All parameters were determined within the same culture. Measurements were always made using cells in the early exponential phase. The cell densities were such that all cells received similar light intensities as shelf-shading did not yet play a role. For each parameter, samples were taken during the day ( $\mathrm{n}=4$ to 14 , depending on the light regime and the parameter involved), during maximum and minimum irradiances. Differences between treatments were tested for significance by 1-factor ANOVA.

\section{RESULTS}

\section{General growth characteristics}

For both Chaetoceros brevis and Pyramimonas sp., maximum growth rates were recorded under the $1: 1 \mathrm{~h}$ 
light regime (Table 1). The highest rates of $0.62 \mathrm{~d}^{-1}$ were recorded for $C$. brevis. The diatom suffered $30 \%$ growth reduction under the $3: 3 \mathrm{~h}$ light regime (ANOVA, $\mathrm{p}<0.05$ ). In the flagellate Pyramimonas sp., no significant differences were measured between the sinusoidal and 3:3 h light regimes.

Pyramimonas sp. had a significantly larger cell volume and carbon content than Chaetoceros brevis (respectively ca. 200 vs. $60 \mathrm{\mu m}^{3}$ and >40 vs $11 \mathrm{pg} \mathrm{cell}^{-1}$; Table 2). In Pyramimonas sp., the greatest cell volume and carbon content was measured under the 1:1 h light regime (ANOVA, p < 0.05). The carbon to nitrogen ratio was rather variable in $C$. brevis and was not significantly affected by the light regime. In the flagellate, the highest carbon to nitrogen ratio (7.32) was observed under the 3:3 h light regime (ANOVA, p < 0.05). Chl a per cell and the ratio of chl a to POC were not significantly affected by the light regimes, in either species (Table 2).

\section{Fluorescence analyses}

As for growth, the highest values for the maximum quantum yield of photosynthesis $\left(\Phi_{\mathrm{m}}\right)$ were recorded under the 1:1 h light regime, with the highest value for Chaetoceros brevis (ANOVA, $\mathrm{p}<0.05$; Table 1; daily average). For both the diatom and the flagellate, lowest values were recorded under the sinusoidal light regime. The generally low values for $\Phi_{\mathrm{m}}$ compare poorly to relatively high values $(\sim 0.6)$ in open ocean areas (Falkowski \& Kolber 1995) but are not unknown in the Antarctic realm (0.1 to 0.3 ; e.g. Sosik \& Olson 2002). The relatively high growth rates confirm the healthy status of the cells.

A diel rhythm was observed under all light conditions (Fig. 1), with decreasing values of $\Phi_{\mathrm{m}}$ coinciding with increases in irradiance (significant negative relationship between PFD and $\Phi_{\mathrm{m}}$ ANOVA, $\left.\mathrm{p}<0.05\right)$. Under the 3:3 h light regime, no close relation between photosynthetic efficiency and PFD was observed; $\Phi_{\mathrm{m}}$ was still dominated by the solar sine (Fig. 1c,d). During the day, the strongest decrease (ca. $50 \%$ ) was recorded in Pyramimonas sp. The decrease for the diatom measured 30 to $35 \%$. Photosynthesis was much more dynamic under the $1: 1 \mathrm{~h}$ light regime (Fig. 1e,f); although the influence of the solar sine was still apparent, $\Phi_{\mathrm{m}}$ closely followed the more rapid fluctuations of PFD. Again, the dynamics were more pronounced for Pyramimonas sp. than for Chaetoceros brevis (a 40 vs $30 \%$ decrease). For both species, minimum and maximum fluorescence values were inversely related to the PFD, under both the $3: 3 \mathrm{~h}$ and 1:1 $\mathrm{h}$ light regimes (Fig. 2).

Table 1. Chaetoceros brevis and Pyramimonas sp. Growth efficiency parameters. $\mu: \mathrm{d}^{-1} ; \bar{a}_{\mathrm{ph}}: \mathrm{m}^{2} \mathrm{mg}^{-1} \mathrm{chl} a_{;} A Q_{\mathrm{ph}}$ : mmol photons mol C ${ }^{-1} \mathrm{~s}^{-1} ; \Phi_{\mu}$ : $\mu \mathrm{mol} \mathrm{C}$ mol quanta ${ }^{-1} ; \mu^{\mathrm{C}}$ (see 'Discussion'): $\mathrm{d}^{-1}$. Values are means \pm SD. Values for growth are based on triplicate growth curves (4 to 6 data points). Values for fluorescence yield and those related to absorption parameters are based on 3 experiments ( 7 to 14 data points over the day)

\begin{tabular}{|lccccccc}
\hline & & $\mu$ & $\Phi_{\mathrm{m}}$ & $\bar{a}_{\mathrm{ph}}$ & $A Q_{\mathrm{ph}}$ & $\Phi_{\mu}$ & $\mu^{\mathrm{C}}$ \\
\hline Chaetoceros brevis & Sinusoidal & $0.55(0.03)$ & $0.10(0.04)$ & 0.018 & 0.1540 & 0.0516 & 6.32 \\
& $3: 3 \mathrm{~h}$ & $0.47(0.03)$ & $0.21(0.05)$ & 0.024 & 0.1822 & 0.0373 & 5.31 \\
& $1: 1 \mathrm{~h}$ & $0.62(0.01)$ & $0.25(0.03)$ & 0.020 & 0.1835 & 0.0488 & 7.12 \\
Pyramimonas sp. & Sinusoidal & $0.22(0.01)$ & $0.12(0.05)$ & 0.023 & 0.2138 & 0.0149 & 9.01 \\
& $3: 3 \mathrm{~h}$ & $0.25(0.03)$ & $0.19(0.05)$ & 0.014 & 0.1390 & 0.0260 & 10.68 \\
& $1: 1 \mathrm{~h}$ & $0.29(0.03)$ & $0.20(0.04)$ & 0.013 & 0.1356 & 0.0309 & 14.35 \\
& & & & & & & \\
\hline
\end{tabular}

Table 2. Chaetoceros brevis and Pyramimonas sp. Biochemical characteristics. Values are means \pm SD, based on 3 experiments (4 to 14 data points over the day)

\begin{tabular}{|c|c|c|c|c|c|c|c|}
\hline & & $\begin{array}{l}\text { Cell volume } \\
\qquad\left(\mu \mathrm{m}^{3}\right)\end{array}$ & $\begin{array}{c}\text { POC } \\
\left(\text { pg cell }^{-1}\right)\end{array}$ & $\begin{array}{l}C: N \\
(w: w)\end{array}$ & $\begin{array}{l}\text { Chlorophyll a } \\
\quad\left(\text { pg cell }{ }^{-1}\right)\end{array}$ & $\begin{array}{l}\text { Chlorophyll a } \\
\quad\left(\mathrm{ng} \mu \mathrm{m}^{-3}\right)\end{array}$ & $\mathrm{Chl} \mathrm{a/POC}$ \\
\hline \multirow[t]{3}{*}{ Chaetoceros brevis } & Sinusoidal & $62.6(2.54)$ & $11.49(2.12)$ & $5.40(0.35)$ & $0.20(0.04)$ & 3.23 & $0.018(0.001)$ \\
\hline & $3: 3 \mathrm{~h}$ & 58.06 (3.89) & 11.29 (1.49) & $6.85(1.26)$ & $0.18(0.04)$ & 3.07 & $0.017(0.003)$ \\
\hline & $1: 1 \mathrm{~h}$ & $58.73(0.10)$ & 11.49 (1.09) & $6.80(1.47)$ & $0.22(0.01)$ & 3.76 & $0.015(0.005)$ \\
\hline \multirow[t]{3}{*}{ Pyramimonas sp. } & Sinusoidal & $206.27(8.27)$ & $40.94(2.77)$ & $6.21(0.55)$ & $0.79(0.14)$ & 3.82 & $0.019(0.005)$ \\
\hline & $3: 3 \mathrm{~h}$ & $199.9(2.64)$ & $42.71(6.09)$ & $7.32(0.95)$ & $0.88(0.11)$ & 4.42 & $0.025(0.007)$ \\
\hline & $1: 1 \mathrm{~h}$ & $198.58(5.73)$ & $49.48(4.47)$ & $6.40(0.25)$ & $1.09(0.32)$ & 5.47 & $0.020(0.004)$ \\
\hline
\end{tabular}




\section{Pigment composition}

Besides chlorophyll a (chl a), Chaetoceros brevis contained the light-harvesting pigments chl $C_{2}$ and fucoxanthin, and the photoprotectors diadinoxanthin and diatoxanthin ( $\mathrm{dd}$ and $\mathrm{dt}_{\text {; }}$ Table 3 ). Pyramimonas contained chl $a$, chlorophyll b ( $\mathrm{chl} b$ ), neoxanthin and lutein, and the photoprotectors violaxanthin, antheraxanthin and zeaxanthin (VAZ-pool) (Table 3).

Both the cellular pigment content as well as pigment concentration was significantly higher in Pyramimonas sp. than in Chaetoceros brevis (ANOVA, p $<0.05$; Tables 2 \& 3). In C. brevis, no clear response towards the various light regimes was observed. An average chl a content of ca. 0.2 pg cell ${ }^{-1}$ was recorded under all light conditions. In Pyramimonas sp., a significant increase in the cellular content of all pigments but violaxanthin was recorded under the $3: 3 \mathrm{~h}$ and 1:1 h light regimes (ANOVA, p < 0.05). A minimum value of 0.79 pg chl a cell ${ }^{-1}$ was recorded under the sinusoidal light regime.

Active xanthophyll cycling was observed in both species under all light regimes (Fig. 3) (ANOVA, p < 0.05). In Chaetoceros brevis, a significant relationship between a high ratio of dt to dd and a high PFD was observed. The ratio fluctuated between 5 and $100 \%$ of the maximum (Fig. 3a,c,e). Maximum quenching potential was measured under the sinusoidal light regime (the average $\mathrm{dt}$ :dd ratio was 0.25$)$. A low average $\mathrm{dt}$ :dd ratio of 0.08 was measured under the $3: 3 \mathrm{~h}$ light regime. A ratio of 0.15 was recorded for the $1: 1 \mathrm{~h}$ light regime. In Pyramimonas sp., the VAZ-pool displayed the highest dynamics under the 3:3 h light regime (Fig. 3d). Under the 1:1 h light regime, no direct relationship between the zea:VAZ ratio and PFD could be observed, other than the diel cycle. The zea:VAZ ratio varied between
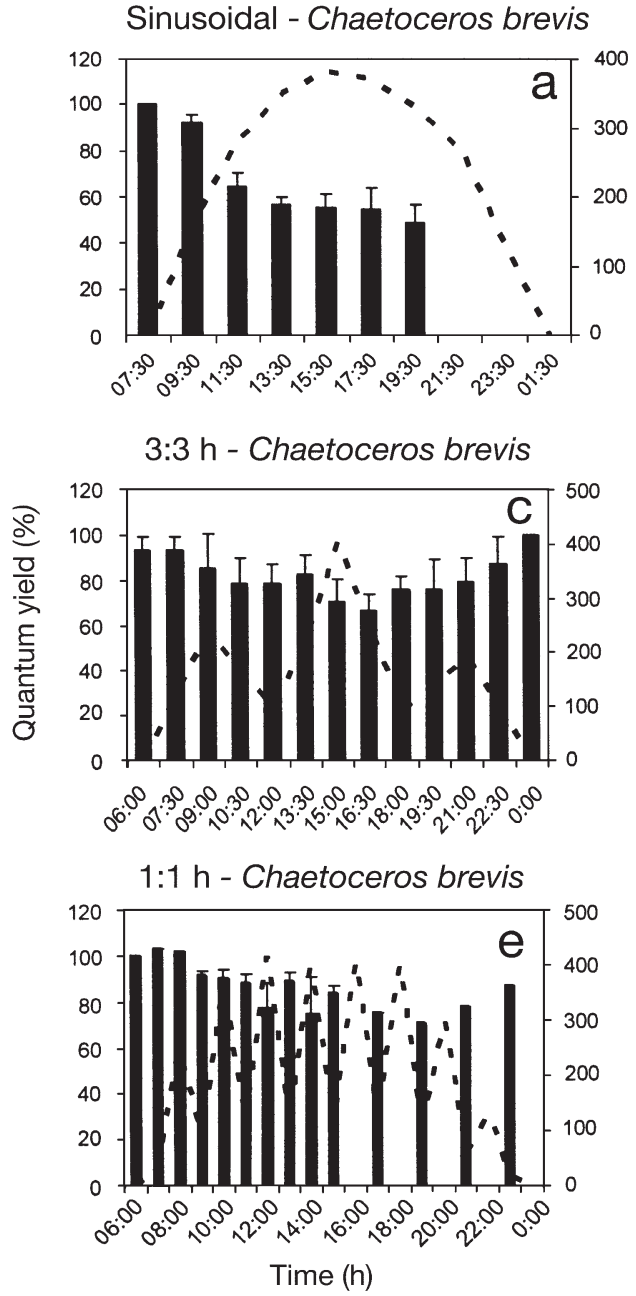

Sinusoidal - Pyramimonas sp.

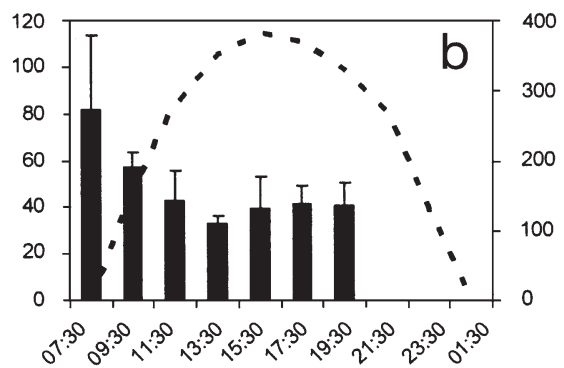

\section{3:3 h - Pyramimonas sp.}

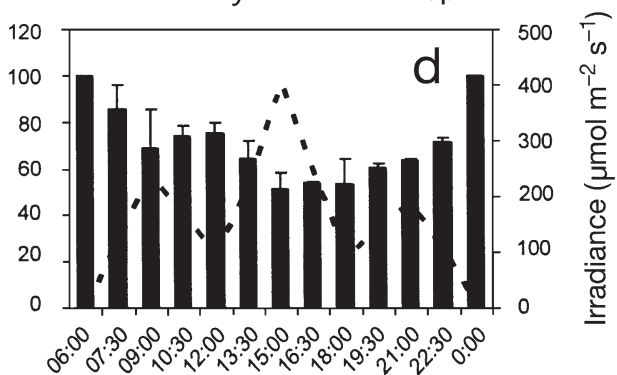

1:1 h - Pyramimonas sp.

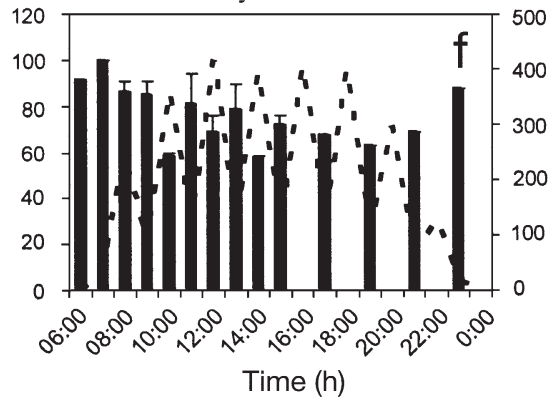

Fig. 1. Chaetoceros brevis and Pyramimonas sp. The maximum quantum yield of photosynthesis (bars) determined over the day under 3 different light regimes (sinusoidal, 3:3 h and 1:1 h) plotted alongside irradiance (---). Fluorescence dynamics are expressed in percentages, taking the maximum morning values as reference (i.e. $100 \% ; n=3$ ). Blank columns indicate no samples taken 


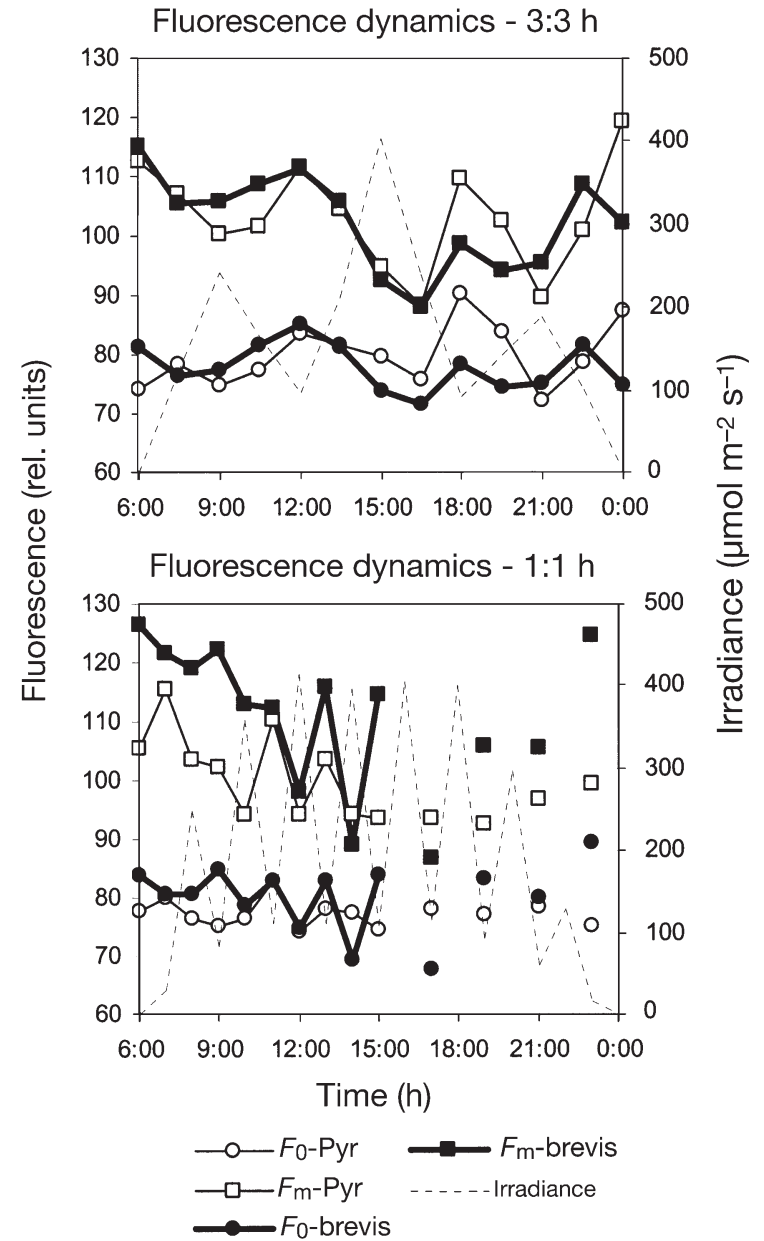

Fig. 2. Chaetoceros brevis and Pyramimonas sp. Fluorescence dynamics of photosynthesis $\left(F_{0}\right.$ and $\left.F_{\mathrm{m}}\right)$, determined over the day under 2 different light regimes (3:3 $\mathrm{h}$ and 1:1 h), plotted alongside irradiance spectra did not change over the day (data not shown). When normalized to chl a absorption at $670 \mathrm{~nm}$ (Fig. 5c,d), no response towards the different light regimes was observed; similar spectra were recorded for both C. brevis and Pyramimonas sp. The absorption cross-section was inversely related to the chl a concentration (compare Tables 1 \& 2).

When normalized to cellular carbon, the total amount of photons absorbed was higher for Chaetoceros brevis than for Pyramimonas sp. under both the $3: 3 \mathrm{~h}$ and $1: 1 \mathrm{~h}$ light regimes (Table 1: $A Q_{\mathrm{ph}}$ ). The quantum efficiency of growth was higher for the diatom than for the flagellate under all conditions (Table 1: $\Phi_{\mu}$ ). Very low values for $\Phi_{\mu}$ were measured for Pyramimonas sp. under the sinusoidal light regime, which related to the relatively high values of $\bar{a}_{\text {ph }}$ (see also Fig. 5).

\section{Carbohydrates}

The dynamics in the intracellular dissolvable carbohydrates quota showed a similar trend in Chaetoceros brevis and Pyramimonas sp. under both the $3: 3 \mathrm{~h}$ and 1:1 h light regimes. The carbohydrate quota increased until midday and remained constant thereafter (data not shown). Whereas the quotas were highest in the flagellate, the build-up of carbohydrates over the day was much higher in C. brevis than in Pyramimonas sp. (Table 4). In the diatom, afternoon values increased to between 150 and $200 \%$ of the morning values. A modest increase of 35 to $50 \%$ was measured in the flagellate. Cell quota, as well as the measured increase of carbohydrates over the day, was stronger under the 1:1 h than under the 3:3 h light regime (Table 4).
10 and $100 \%$. The ratio averaged 0.6 at midday and was similar under all conditions.

When normalized to chl $a$, the total pool of photoprotective pigments was higher for Chaetoceros brevis than for Pyramimonas sp. (Fig. 4).

\section{Light absorption}

The chl a-specific absorption capacity was higher for Chaetoceros brevis than for Pyramimonas sp. under the $3: 3 \mathrm{~h}$ and $1: 1 \mathrm{~h}$ light conditions (Fig. 5a,b; Table 1: $\bar{a}_{\mathrm{ph}}$ ). Distinct peaks were recorded at $675 \mathrm{~nm}(\mathrm{chl}$ a), $650 \mathrm{~nm}$ (chl b), $470 \mathrm{~nm}$ (carotenoids) and $430 \mathrm{~nm}$ (chl a). The absorption
Table 3. Chaetoceros brevis and Pyramimonas sp. Cellular pigment content (pg cell $^{-1}$ ). Values are means $\pm \mathrm{SD}$, based on 3 experiments (4 to 14 data points over the day). A slight increase in pigment content over the day was determined not to be significant

\begin{tabular}{|lccc|}
\hline & Sinusoidal & $3: 3 \mathrm{~h}$ & $1: 1 \mathrm{~h}$ \\
\hline $\begin{array}{l}\text { Chaetoceros brevis } \\
\text { chl } c_{2}\end{array}$ & $0.023(0.004)$ & $0.025(0.004)$ & $0.029(0.002)$ \\
fucoxanthin & $0.095(0.013)$ & $0.104(0.017)$ & $0.115(0.003)$ \\
diadinoxanthin & $0.058(0.006)$ & $0.051(0.001)$ & $0.052(0.008)$ \\
diatoxanthin & $0.010(0.003)$ & $0.003(0.001)$ & $0.005(0.002)$ \\
chl $a$ & $0.202(0.044)$ & $0.178(0.042)$ & $0.221(0.006)$ \\
Pyramimonas sp. & & & \\
neoxanthin & $0.024(0.013)$ & $0.035(0.003)$ & $0.043(0.015)$ \\
violaxanthin & $0.024(0.010)$ & $0.025(0.011)$ & $0.035(0.003)$ \\
antheraxanthin & $0.023(0.014)$ & $0.035(0.004)$ & $0.049(0.018)$ \\
lutein & $0.046(0.024)$ & $0.062(0.007)$ & $0.074(0.022)$ \\
zeaxanthin & $0.048(0.031)$ & $0.069(0.010)$ & $0.068(0.024)$ \\
chl $b$ & $0.261(0.144)$ & $0.391(0.035)$ & $0.479(0.162)$ \\
chl $a$ & $0.787(0.140)$ & $0.883(0.107)$ & $1.087(0.325)$ \\
& & & \\
\hline
\end{tabular}




\section{DISCUSSION}

The diatom Chaetoceros brevis and the flagellate Pyramimonas sp. displayed different strategies of photoacclimation. In the flagellate, strong down-regulation of potential photosynthetic efficiency was observed during the day. The dynamics in photosynthesis were less pronounced in the diatom. We discuss the hypothesis that the diatom adjusted to the average irradiance received, a strategy that has previously been suggested in other diatom species (e.g. Dijkman 2001). Pyramimonas sp. on the other hand, acclimated readily to changes in light intensity. Following these differences in photoacclimation, a growth reduction during moderate rates of mixing, i.e. the $3: 3 \mathrm{~h}$ light regime, was only observed in $C$. brevis. We argue that the relatively high values for the quantum yield of photosynthesis in themselves do not exclude the possibility of photodamage. Higher turnover rates and enhanced investment in maintenance costs (Kana et al. 2002) can serve in sustaining high photosynthetic rates, yet will result in reduced growth rates due to enhanced losses associated with increases in respiration.

Pyramimonas sp. displayed strong kinetics in photosynthetic parameters during the day. A morning increase in PFD was always closely matched by a decrease in photosynthetic efficiency that recovered again with decreasing PFD in the late afternoon. Such diel rhythms in photosynthetic efficiency have previously been described; they primarily serve to prevent photoinhibition during maximum irradiance at midday (e.g. Harding et al. 1987, Prézelin 1992). A similar
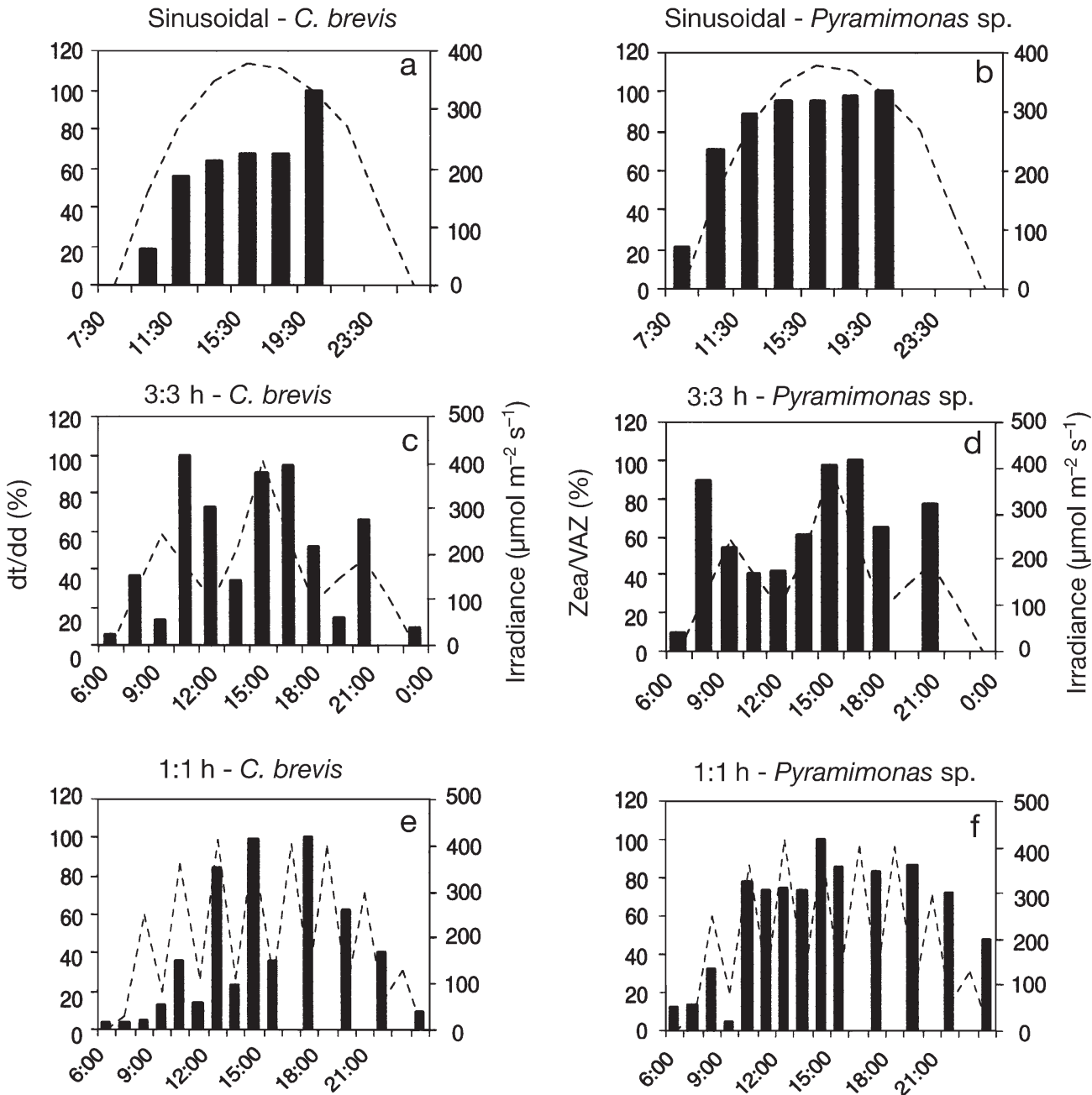

Time (h)

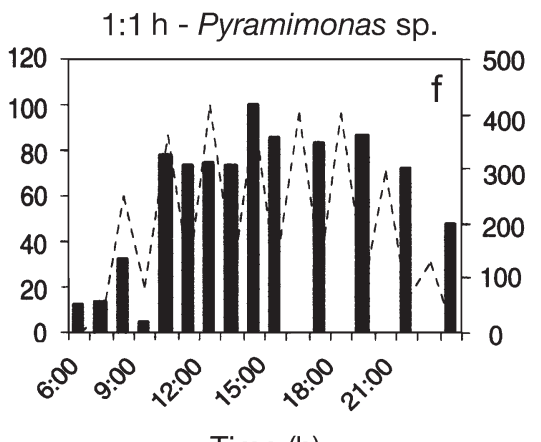

Time (h)

Fig. 3. Chaetoceros brevis and Pyramimonas sp. Dynamics of the xanthophyll cycle in C. brevis (ratio of diatoxanthin to diadinoxanthin, dt: dd) and Pyramimonas sp. (zeaxanthin [zea] as a fraction of the VAZ-pool; see 'Results' section 'Pigment composition'). The ratios are expressed as percentages of maximum values at midday plotted alongside irradiance $(\mathrm{n}=3$ ). The maximum dt:dd ratio in C. brevis appeared relatively late in the afternoon. Note that in (c) and (d), dt and zea were sometimes below detection limit at the end of the day. Blank columns in $a, b$, e and $f$ indicate no samples taken 
strong correlation between $\Phi_{\mathrm{m}}$ and PFD was observed during the rapid changes of irradiance experienced under the $3: 3 \mathrm{~h}$ and 1:1 $\mathrm{h}$ light regimes. The high activity of the photoprotective pigment cycle (conversion of violaxanthin into the heat-dissipating pigment zeaxanthin) suggested active control of photosynthetic

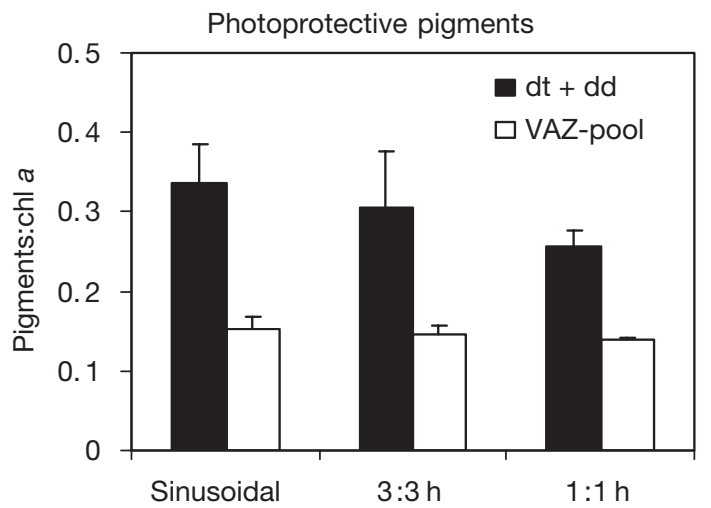

Fig. 4. Chaetoceros brevis and Pyramimonas sp. Ratio of photoprotective pigments to chl $a$ in $C$. brevis (diato- plus diadinoxanthin) and Pyramimonas sp. (VAZ-pool) ( $\mathrm{n}=2$ to 4 ). The apparent trend (C. brevis: highest ratio at the sinusoidal light regime) was found to be insignificant (ANOVA, p > 0.05) efficiency (Demmig-Adams \& Adams 1996). Besides the quenching by zeaxanthin, other processes must have contributed to the down-regulation in Pyramimonas sp. under the 1:1 h light regime, the fluctuating fluorescence signal was not directly correlated to the conversion of violaxanthin to zeaxanthin. The deepoxidation process is not fast enough to keep pace with the changes in irradiance imposed on the algae. State transition may explain the decrease in $F_{0}$ and $F_{\mathrm{m}}$ and concordant decreases in $\Phi_{\mathrm{m}}$. State transition is an efficient quenching mechanism that can occur within minutes and offers the additional advantage of continued energy production in a controlled way (Allen et al. 1981, Saito et al. 1983). Continued activity of photosystem I allows the production of ATP via cyclic electron flow and thus, constitutes a favorable means of photoacclimation. Alternative processes that serve to avoid photodamage in the short-term (e.g. migration of photosynthetic units) require a mobility of photosystems as has been described for higher plants (Anderson et al. 1995). Indeed, green algae possess a flexible photosynthetic apparatus and such alternative processes may, therefore, well be envisioned to play a role.

Photosynthetic efficiency varied much less in the diatom. The variation in $\Phi_{\mathrm{m}}$ in relation to PFD was only
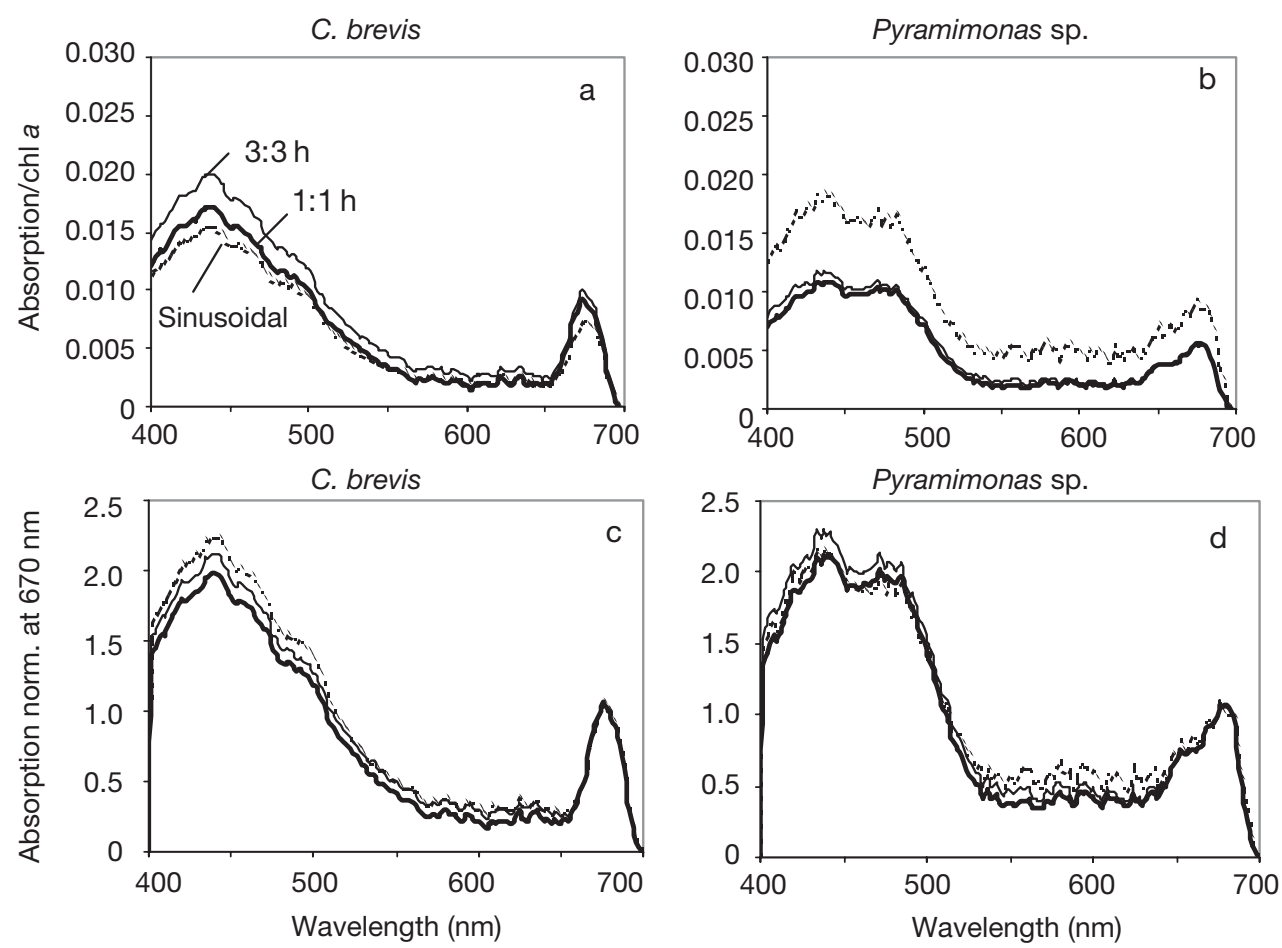

Fig. 5. Chaetoceros brevis and Pyramimonas sp. In vivo absorption spectra under various light regimes (sinusoidal, $3: 3 \mathrm{~h}$ and $1: 1 \mathrm{~h})$. (a,b) Absorption per chl $a_{i}(\mathrm{c}, \mathrm{d})$ spectra normalized to the $670 \mathrm{~nm}$ peak of chl $a$. Note the relatively high absorption coefficient of Pyramimonas sp. which was likely due to an underestimation of cell number, and consequent chl a ml ${ }^{-1}$ 
Table 4. Chaetoceros brevis and Pyramimonas sp. Cellular content of intracellular dissolvable sugars $\left(\mathrm{pg}\right.$ cell $\left.^{-1}\right)$. Values are means $\pm \mathrm{SD}$, based on 3 experiments ( 4 to 14 data points over the day

\begin{tabular}{|c|c|c|c|}
\hline & $\begin{array}{c}\text { Start of } \\
\text { photoperiod }\end{array}$ & $\begin{array}{c}\text { End of } \\
\text { photoperiod }\end{array}$ & Increase \\
\hline \multicolumn{4}{|c|}{ Chaetoceros brevis } \\
\hline $3: 3 \mathrm{~h}$ & $1.29(0.014)$ & $3.80(0.039)$ & $2.52(0.025)$ \\
\hline $1: 1 \mathrm{~h}$ & $2.99(0.030)$ & $6.81(0.069)$ & $3.82(0.039)$ \\
\hline \multicolumn{4}{|c|}{ Pyramimonas sp. } \\
\hline $3: 3 \mathrm{~h}$ & $4.68(0.022)$ & $6.28(0.029)$ & $1.60(0.007)$ \\
\hline $1: 1 \mathrm{~h}$ & $6.49(0.025)$ & $9.62(0.037)$ & $3.13(0.012)$ \\
\hline
\end{tabular}

ca. $30 \%$; in Pyramimonas sp. this was up to $50 \%$. Diatoms do not show the heterogeneity in photosynthetic membranes typical of green plants and green algae; membrane systems are apparently less flexible (Briantais et al. 1982, Anderson et al. 1995). This implies that only limited means of rapid photoacclimation are available for Chaetoceros brevis. The main process of non-photochemical quenching in this species consisted of heat dissipation through the photoprotective pigment cycle of $\mathrm{dt}$ to $\mathrm{dd}$. The conversion of diadinoxanthin into diatoxanthin usually takes less than a few minutes (Demers et al. 1991, Olaizola et al. 1994). In our study, the dt to dd cycle was found to be effective under all light regimes. Despite the variations in growth response, the cellular pigment signatures were similar under all light regimes and the ratio of photoprotectors to chl a was not significantly affected by the light. No sign of an induction of xanthophyll pigments was discerned, not even under the potentially stressful 3:3 h light regime. Moreover, a maximum dt:dd ratio of 0.25 is not exceptionally high (in C. brevis, ratios up to 0.5 have been observed: M.A. van Leeuwe, W.H. van de Poll unpubl. data). Even so, an increase in xanthophyll cycle pigments would have been discernable in the Soret region of the absorption spectra; no such change in the spectra was observed.

These results suggest that the diatom adapted to the average light intensity rather than to the maximum irradiance. This confirms previous findings by Ibelings et al. (1994) and Dijkman (2001). Notably, this strategy renders diatoms vulnerable to photoinhibition. The occurrence of photodamage may explain the observed growth reduction. During exposure to high irradiance, down-regulation of photosynthetic efficiency is required to prevent the generation of an energy excess that can result in radical formation and consequent photodamage. Such damage is not necessarily reflected in a reduction in the quantum yield. It was previously shown by Kana et al. (2002) and Behrenfeld et al. (1998) that algae find many ways to optimize carbon fixation. Under a dynamic light regime, cells acclimate in such a way that, during conditions of low light, the light-harvesting capacity is sufficient to generate enough reducing power to support active growth. Simultaneously, during exposure to high irradiance, the consequences of induced photodamage, due to the generation of an energy excess, are compensated for by maintaining a so-called inner capacity of increasing PS II turnover rates (Kana et al. 2002). Alternatively, we suggest that a high photosynthetic efficiency may be maintained by increased turnover rates of protein synthesis (e.g. D1 protein) that allows the immediate repair of damaged photosystems. Both strategies require enhanced maintenance costs that may result in reduced net growth rates. A decoupling between carbon acquisition and the quantum yield of photosynthesis was previously demonstrated by Flameling \& Kromkamp (1998), who also ascribed the mismatch under high light conditions to increased respiration costs.

The impact of photodamage suffered during periods of high irradiance is time-dependent (Han et al. 2000, Marshall et al. 2000). When exposure to high irradiance is only brief, little damage will be suffered and repair processes require relatively few costs. The 1:1 h light regime, used in our study, provided conditions that allowed for the best balance between damage and regeneration processes. These results again conform to previous studies (Ibelings et al. 1994, also modelled by Lizon et al. 1998), where it was also found that rapid fluctuations in irradiance ( 1 to $2 \mathrm{~h}$ light-dark) did not negatively affect growth rates. The 3:3 h light climate was clearly less favorable.

A simple mathematical exercise provides further support for the concept of photoinhibition-related growth reduction. In both species, the quantum efficiency of growth was apparently high; quantum requirements of 20 to 30 and 35 to 70 photons carbon atom $^{-1}$ for Pyramimonas sp. and Chaetoceros brevis, respectively were calculated (20 to 180; see for comparison (Falkowski et al. 1985). Under the $3: 3 \mathrm{~h}$ and $1: 1 \mathrm{~h}$ light regimes, the diatom was more efficient than the flagellate; both $\Phi_{\mathrm{m}}$ and $\Phi_{\mu}$ were always higher for C. brevis than for Pyramimonas sp. In addition, when expressed per unit carbon (i.e. the energy-carrying component of the cell), the diatom showed a higher absorption capacity $\left(A Q_{\mathrm{ph}}\right)$ than the flagellate. Yet, growth rates expressed as a carbon basis $\left(\mu^{\mathrm{C}}\right.$, Table 1$)$ showed apparently contradictory results; $\mu^{\mathrm{C}}$ was higher for Pyramimonas sp. than for C. brevis under all light conditions. The apparent mismatch between $\mu^{\mathrm{C}}$ and the quantum efficiency in $C$. brevis can only be explained by assuming that a large fraction of the fixed carbon was used for respiratory processes rather than converted into growth. Enhanced photodamage expe- 
rienced under variable light conditions can explain the increased demand for energy consumed by maintenance processes. Indeed, the discrepancy between the growth parameters was only observed under the $3: 3 \mathrm{~h}$ and 1:1 $\mathrm{h}$ light regimes. Under the sinusoidal light regime, the relatively low values for $\mu^{\mathrm{C}}$ were, in fact, supported by relatively low values for $\Phi_{\mathrm{m}}, \Phi_{\mu}$ and $A Q_{\mathrm{ph}}$. Under the more stable light conditions, $C$. brevis apparently invested more energy in photoprotection. Additional support for the notion of potential photodamage in $C$. brevis under the $3: 3 \mathrm{~h}$ light regime was provided by the relatively high accumulation of carbohydrates during the day (the increase under this light regime was almost double the morning values, compared to Pyramimonas sp.). The strong diel signal suggests unbalanced growth in the diatom, which can be ascribed to a higher investment in repair processes that continue through the night (Cosper 1982, Ibelings et al. 1994). The metabolic processes that are involved in the repair of photodamage require a high turnover of the low molecular weight pool, in order to replace damaged proteins that make-up the photosynthetic apparatus. Respiratory processes may form an important sink of photosynthetic energy that can be highly variable between species (e.g. Flameling \& Kromkamp 1995, Milligan \& Cosper 1997, Flameling \& Kromkamp 1995) and may have played a significant role in controlling net growth in C. brevis.

\section{ECOLOGICAL IMPLICATIONS}

In the open ocean, light conditions are generally highly variable. In this study, it was shown that the flagellate readily acclimated to dynamic light conditions. The diatom rather adjusted to the average light conditions, which supported findings by Dijkman (2001). It was previously suggested that when diatoms seek to optimize rates of carbon fixation (Behrenfeld et al. 1998), they tend to adjust to lower irradiance levels, which leaves them more susceptible to photoinhibition at high irradiance. Due to their high intrinsic growth rates, Chaetoceros brevis will always outcompete Pyramimonas sp., even though the diatom may be experiencing a relatively stronger reduction in growth than the flagellate. Yet, in the open ocean, a major role in biogeochemical cycles is played by the larger bloom-forming diatom species. Larger species generally have a lower growth rate and assuming that repair correlates with growth, it is expected that they will suffer more under variable light conditions. If our findings on $C$. brevis are indeed to be extrapolated to larger diatoms, we may begin to understand why such diatoms only form large blooms under stable light conditions, such as those encountered in frontal systems or near the ice edge.
Acknowledgements. We thank R.Visser for pigment analyses. M.A.vL. was supported by a grant (\# 751.498.01) from the 'Commissie Antarctisch Onderzoek' of the Netherlands Organisation for Scientific Research (NWO).

\section{LITERATURE CITED}

Admiraal W, Werner D (1983) Utilization of limiting concentrations of ortho-phosphate and production of extracellular organic phosphates in cultures of marine diatoms. J Plankton Res 5:495-513

Allen JF (1995) Thylakoid protein phosphorylation, state 1state 2 transitions, and photosystem stoichiometry adjustment: redox control at multiple levels of gene expression. Physiol Plant 93:196-205

Allen JF, Bennett J, Steinback KE, Arntzen CJ (1981) Chloroplast protein phosphorylation couples plastoquinone redox state to distribution of excitation energy between photosystems. Nature 291:25-29

Anderson JM, Chow WS, Park YI (1995) The grand design of photosynthesis: acclimation of the photosynthetic apparatus to environmental cues. Photosynth Res 46:129-139

Behrenfeld MJ, Prasil O, Kolber ZS, Babin M, Falkowski PG (1998) Compensatory changes in Photosystem II turnover rates protect photosynthesis from photoinhibition. Photosynth Res 58:259-268

Briantais JM, Vernotte C, Maison B (1982) Influence of stacking on the distribution of light energy in the photosynthetic apparatus. Physiol Veg 20:111-122

Buma AGJ, de Baar HJW, Nolting RF, van Bennekom AJ (1991) Metal enrichment experiments in the WeddellScotia Seas: Effects of iron and manganese on various plankton communities. Limnol Oceanogr 36:1865-1878

Cailliau C, Claustre H, Giannino S (1996) Chemotaxonomic analysis of phytoplankton distribution in the Indian sector of the Southern Ocean during late austral summer. Oceanol Acta 20:721-732

Cosper E (1982) Effects of diurnal fluctuations in light intensity on the efficiency of growth of Skeletonema costatum (Grev.) Cleve (Bacillariophyceae) in a cyclostat. J Exp Mar Biol Ecol 65:229-239

Cullen JJ, Lewis MR (1988) The kinetics of algal photoadaptation in the context of vertical mixing. J Plankton Res 10: 1039-1063

Demers S, Roy S, Gagnon R, Vignault C (1991) Rapid lightinduced changes in cell fluorescence and in xanthophyllcycle pigments of Alexandrium excavatum (Dinophyceae) and Thalassiosira pseudonana (Bacillariophyceae): a photo-protection mechanism. Mar Ecol Prog Ser 76: 185-193

Demmig-Adams B, Adams WW (1996) Chlorophyll and carotenoid composition in leaves of Euonymus kiautschovicus acclimated to different degrees of light stress in the field. Australian J Plant Physiol 23:649-659

Demmig-Adams B, Adams WW, Barker DH, Logan BA, Bowling DR, Verhoeven AS (1996) Using chlorophyll fluorescence to assess the fraction of absorbed light allocated to thermal dissipation of excess excitation. Physiol Plant 98: $253-264$

Denman KL, Gargett AE (1983) Time and space scales of vertical mixing and advection of phytoplankton in the upper ocean. Limnol Oceanogr 28(5):801-815

Dijkman NA (2001) The regulation of photosynthesis in diatoms under dynamic irradiance. $\mathrm{PhD}$ thesis. Universität Bremen

Falkowski PG (ed) (1980). Light-shade adaptation in marine 
phytoplankton. In: Primary productivity in the sea. Plenum Press, New York, p 99-119

Falkowski PG, Kolber Z (1995) Variations in chlorophyll fluorescence yields in phytoplankton in the world oceans. Aust J Plant Physiol 22:341-355

Falkowski PG, LaRoche J (1991) Acclimation to spectral irradiance in algae. J Phycol 27:8-14

Falkowski PG, Dubinsky Z, Wyman K (1985). Growthirradiance relationships in phytoplankton. Limnol Oceanogr 30:311-321

Flameling IA (1998) Growth and photosynthesis of eukaryotic microalgae in fluctuating light conditions, induced by vertical mixing. PhD thesis, University of Nijmegen

Flameling IA, Kromkamp J (1995) Regulation of photosynthesis of Phaeocystis globosa in fluctuating light conditions, In: Mathis P (ed) Photosynthesis: from light to biosphere. Kluwer Ac. Publ., Dordrecht, p 797-800

Flameling IA, Kromkamp J (1998) Light dependence of quantum yields for PS II charge separation and oxygen evolution in eukaryotic algae. Limnol Oceanogr 43:284-297

Gallegos CL, Platt T, Harrison WG, Irwin B (1983) Photosynthetic parameters of arctic marine phytoplankton: vertical variations and time scales of adaptation. Limnol Oceanogr 28:698-708

Gilmore AM (1997) Mechanistic aspects of xanthophyll cycledependent photoprotection in higher plant chloroplasts and leaves. Physiol Plant 99:197-209

Green BR, Durnford DG (1996) The chlorophyll-carotenoid proteins of oxygenic photosynthesis. Annu Rev Plant Physiol Plant Mol Biol 47:685-714

Han BP, Virtanen M, Koponen J, Straskraba M (2000) Effect of photoinhibition on algal photosynthesis: a dynamic model. J Plankton Res 22:865-885

Harding LW, Fisher TR Jr, Tyler MA (1987) Adaptive responses of photosynthesis in phytoplankton: specificity to time-scale of change in light. Biol Oceanogr 4:403-437

Hegseth EN (1989) Photoadaptation in marine arctic diatoms. Polar Biol 9:479-486

Henley WJ, Ramus J (1989). Time course of physiological response of Ulva rotundata to growth irradiance transitions. Mar Ecol Prog Ser 54:171-177

Horton P, Ruban AV, Walters RG (1996) Regulation of light harvesting in green plants. Annu Rev Plant Physiol Plant Mol Biol 47:655-684

Ibelings BW, Kroon BMA, Mur LR (1994) Acclimation of photosystem II in a cyanobacterium and a eukaryotic green alga to high and fluctuating photosynthetic flux densities, simulating light regimes induced by mixing lakes. New Phytol 128:407-424

Kana TD, Geider RJ, Critchley C (1997) Regulation of photosynthetic pigments in micro-algae by multiple environmental factors: a dynamic balance hypothesis. New Phytol 137:629-638

Kana R, Lazar D, Prasil O, Naus J (2002) Experimental and theoretical studies on the excess capacity of photosystem II. Photosynth Res 72:271-284

Kraay GW, Zapata M, Veldhuis MJW (1992) Separation of chlorophylls $C_{1}, c_{2}$, and $c_{3}$ of marine phytoplankton by reversed-phase-C18-high-performance liquid chromatography. J Phycol 28:708-712

Editorial responsibility: Victor de Jonge (Contributing Editor), Haren, The Netherlands
Krause GH, Weis E (1991) Chlorophyll fluorescence and photosynthesis: The basics. Annu Rev Plant Physiol Plant Mol Biol 42:313-349

Kroon BMA (1994) Variability of photosystem II quantum yield and related processes in Chlorella pyrenoidosa (Chlorophyta) acclimated to an oscillating light regime simulating a mixed photic zone. J Phycol 30:841-852

Lancelot C, Hannon E, Becquevort S, Veth C, de Baar HJW (2000) Modelling phytoplankton blooms and carbon export production in the Southern Ocean: dominant controls by light and iron in the Atlantic sector in Austral spring 1992. Deep-Sea Res I 47:1621-1662

Liu D, Wong PTS, Dutka BJ (1973) Determination of carbohydrates in lake sediment by modification of the phenolsulphuric acid method. Water Res 7:741-746

Lizon F, Seuront L, Lagadeuc Y (1998) Photoadaptation and primary production study in tidally mixed coastal waters using a Lagrangian model. Mar Ecol Prog Ser 169:43-54

Marra J (1978) Phytoplankton photosynthetic response to vertical movement in a mixed layer. Mar Biol 46:203-208

Marra J (1980) Time course of light intensity adaptation in a marine diatom. Mar Biol Lett 1:175-183

Marshall HL, Geider RJ, Flynn KJ (2000) A mechanistic model of photoinhibition. New Phytol 145:347-359

Milligan AJ, Cosper EM (1997) Growth and photosynthesis of the 'brown tide' microalga Aurecoccus anophagefferens in subsaturating constant and fluctuating irradiance Mar Ecol Prog Ser 153:67-75

Mitchell BG, Brody EA (1991) Light limitation of phytoplankton biomass and macronutrient utilization in the Southern Ocean. Limnol Oceanogr 36:1662-1677

Muller P, Li XP, Niyogi KK (2001) Non-photochemical quenching. A response to excess light energy. Plant Physiol 125:1558-1566

Olaizola M, La Roche J, Kolber Z, Falkowski PG (1994) Nonphotochemical fluorescence quenching and the diadinoxanthin cycle in a marine diatom. Photosynth Res 41: $357-370$

Post AF, Dubinsky Z, Wyman K, Falkowski PG (1984) Kinetics of light-intensity adaptation in a marine diatom. Mar Biol 83:231-238

Prézelin BB (1992). Diel periodicity in phytoplankton productivity. Hydrobiologia 238:1-35

Richardson K, Beardall J, Raven JA (1983) Adaptation of unicellular algae to irradiance: an analysis of strategies. New Phytol 93:157-191

Saito K, Williams WP, Allen JF, Bennett J (1983) Comparison of ATP-induced and state 1/state 2-related changes in excitation energy distribution in Chlorella vulgaris. Biochim Biophys Acta 724:94-103

Sosik HM, Olson RJ (2002). Phytoplankton and iron limitation of photosynthetic efficiency in the Southern Ocean during late summer. Deep-Sea Res I 49:1195-1226

Trtílek M, Kramer DM, Koblízek M, Nedbal L (1997) Dualmodulation LED kinetic fluorometer. J Lum 72-74: 597-599

van Oijen T, van Leeuwe MA, Gieskes WWC (2003) Variation of particulate carbohydrate pools over time and depth in a diatom-dominated plankton community at the Antarctic Polar Front. Polar Biol 26:195-201

Submitted: October 17, 2003; Accepted: August 10, 2004 Proofs received from author(s): February 22, 2005 